\title{
Sentiment Analysis of Music Criticism Based on Data Mining
}

\author{
Yao Liang \\ Wuhan University of Technology \\ School of Management \\ Wuhan, China \\ 269493944@qq.com
}

\author{
Hu Wang \\ Wuhan University of Technology \\ School of Management \\ Wuhan, China
}

\begin{abstract}
With the development of web2.0, more and more people like to express their emotions by making comments anytime and anywhere. Music comments are an emotional expression of the listener's mood for listening to songs. On the basis of the original Hevner emotion loop, this paper proposes an optimized emotional model that fits Chinese people's thinking and language habits, constructs a new musical sentiment dictionary, analyzes the polarity of musical emotions, and proposes an emotional vector space model based on emotional units. Through experiments, it is proved that the emotional vector space model has higher accuracy and convenience than artificial emotion annotation.
\end{abstract}

Keywords - commentary emotion mining; space vector model; musical emotion classification

\section{INTRODUCTION}

With the popularity of mobile communications, there is a large amount of review information on the Internet, which contains rich emotional information waiting for mining analysis. In the face of massive lightweight review information, it is not only time-consuming and labor-intensive but also less accurate to analyze through manual annotation. Therefore, it is very necessary to use computer technology to conduct emotional excavation of comments. Music is a ubiquitous multimedia expression in people's lives. Therefore, the application of online music plays a more rapid and rapid development after the arrival of the Internet era. At present, the analysis and processing technology of multimedia information in music has become a very important research hotspot.

\section{RELATED RESEARCH}

Online reviews usually refer to the evaluation information that consumers post after purchasing goods on the Internet platform. For the accurate definition of online reviews, different scholars have different opinions. Lee and BradLow defined online commentary as: free, unsolicited, user-generated online content ${ }^{[1]}$. Depending on the type of content being reviewed, online reviews can be divided into two types of attribute-based and perceptual reviews. The former is a description of the objective product information of the service product, and the latter is the subjective emotional experience of the consumer and the product. Overall assessment ${ }^{[2]}$. Zhang Yanhui believes that consumers' bad reviews and upload pictures have a stronger effect on the usefulness of reviews ${ }^{[3]}$. Different scholars have different understandings of text sentiment analysis. Wang Hongwei et al. ${ }^{[4]}$ believe that sentiment analysis is to analyze the opinions of users to determine implicit emotional information in order to find out the user's emotional changes; Zhang Ziqiong et al. ${ }^{[5]}$ think that Sentiment analysis is based on the automatic analysis of product reviews to discover consumer attitudes and opinions; Fan et al. ${ }^{[6]}$ analyzed the users of feedback forums on the Automotive Forum. The research corpus they selected was from the United States in 2010. The Department of Energy, the National Highway Safety Department and other databases in the United States are mainly responsible for the study of more than 500, 000 words of research corpus.

Another important part of this article is to explore musical emotion recognition and personalized music recommendations. In the past, in the process of sentiment analysis of music, the analysis results were not clear and accurate only based on people's subjective judgment. Therefore, the study of musical emotion recognition is very necessary and has great research value.

\section{MUSICAL EMOTION RESEARCH}

Music is the art of human's most essential emotion, which often conveys a rich and complex inner emotional world. In real life, people will express their inner feelings through comments after listening to music. Under normal circumstances, people's perceptions of musical emotions are very subjective, and the resulting emotional characteristics are not accurate enough and are vague, so the deviation is large.

\section{A. Music sentiment analysis model}

\section{1) Hevner emotion loop}

Hevner emotion loop is a cognitive psychology model of music emotion research. It analyzes people's music psychology and obtains the emotional characteristics of music. At present, the classic models in the field of emotional music research mainly include Hevner's emotion loop and Thayer's energy and pressure model. Hevner's emotional model adopts a ring structure. There are eight links in the structure, which represent different musical emotions. Each emotion is closely related to the preceding and following links. The eight emotions can undergo a gradual transition and form a ring. . Has a high research value and reference. 


\section{2) Thayer model}

The Thayer model includes two dimensions of energy and pressure, which are used to represent the emotional characteristics of music. However, the main problem of this model is that people's emotions are diverse and rapidly changing. The sources of emotions are also very widespread. It is not just the latitudes of energy and pressure. Therefore, the Thayer model has limitations and its expression the emotional characteristics are not accurate and comprehensive.

\section{B. Building a musical emotion dictionary}

This article starts with the expressions commonly used by Chinese people, and re-modifies and optimizes Hevner's emotional model and its emotional subcategories through emotional analysis of light music reviews to determine the emotional intensity of different adjectives expressed in music light reviews and people the degree of psychological recognition of adjectives allows for further research and analysis.

In the emotional analysis of music, we selected a total of 30 different styles of songs from relevant music websites, and collected a total of 12,709 light comments under the songs, statistical analysis of the most common emotional words, and the original Hevner The emotional model is optimized into five emotional categories. A new musical emotion dictionary has been formed as shown in Table I:

TABLE I. MUSICAL EMOTION DICTIONARY TABLE

\begin{tabular}{|c|l|l|l|l|l|l|l|l|}
\hline \multicolumn{7}{|c|}{ Emotional vocabulary } & $\begin{array}{c}\text { Basic } \\
\text { word } \\
\text { set }\end{array}$ \\
\hline 1 & solemn & noble & serene & large & holy & stately & awe & sacred \\
\hline 2 & desolate & pathos & lost & gloomy & bitter & sad & lonely & grief \\
\hline 3 & moving & gentle & dream & subtle & tender & quiet & revel & lyrical \\
\hline 4 & jocular & funny & festal & smart & lively & bright & novel & brisk \\
\hline 5 & strong & passion & grand & superb & forceful & vitality & excited & heated \\
\hline
\end{tabular}

\section{Music Emotion Polarity Analysisuations}

In conducting sentiment analysis, we first analyze the polarity of the text, determine the meaning or derogatory meaning of the text by analyzing the keywords, and define the positive and negative aspects of the emotion. . However, in musical emotions, unlike ordinary emotional tendencies (positive emotions, neutral emotions, and negative emotions), the emotions that people reveal after listening to songs are more likely to be relaxed positive emotional tendencies and repressed negative emotional tendencies.

For the emotional model we have optimized and the sentiment dictionary proposed above, after consulting the opinions of music professionals, we divided the emotional dictionary model with emotional polarity into a new model, as shown in Table:

TABLE II.

EMOTIONAL DICTIONARY WITH EMOTIONAL POLARITY

\begin{tabular}{|l|l|l|l|l|l|l|l|l|}
\hline & \multicolumn{9}{|c|}{ Emotional vocabulary } & Basic word set \\
\hline $\mathrm{N}$ & solemn & noble & serene & large & holy & stately & awe & sacred \\
\hline \multirow{3}{*}{} & desolate & pathos & lost & gloomy & bitter & sad & lonely & grief \\
\hline \multirow{2}{*}{$\mathrm{P}$} & moving & gentle & dream & subtle & tender & quiet & revel & lyrical \\
\cline { 2 - 9 } & jocular & funny & festal & smart & lively & bright & novel & brisk \\
\cline { 2 - 9 } & strong & passion & grand & superb & forceful & vitality & excited & heated \\
\hline
\end{tabular}

$\mathrm{N}$ : negative

P: positive

\section{MUSIC COMMENTARY EMOTION MINING}

Based on the original vector space model (VSM), this paper optimizes the sentiment analysis of music light comments and proposes a new emotional vector space model.

\section{A. Emotion Vector Space Design Principles}

The emotion vector space model proposed in this paper considers the following design principles when designing:

1) In the analysis of emotional characteristics, only the key words in the list of emotional vocabularies listed above are considered for the impact of the light commentary sentiment analysis.

2) The music selected in this article is dominated by popular songs, and does not include large musical pieces with rich emotions. Therefore, the emotions are relatively simple. Generally, each song contains only one kind of emotional sub-category by default.
3) In this paper, the influence of negative words and modifiers in the commentary text on emotion is included in the design scope.

\section{B. Emotional Vector Space Model}

After comparing the advantages and disadvantages of the different methods of the vector space model, the emotion space vector model chosen is characterized by emotional words. The emotion features in the song reviews constitute a highdimensional space vector model. One of the emotional features corresponds to a space. Dimensions, each comment corresponds to a vector in space.

We define the music light comment (D) as a triple:

$$
\mathrm{D}=\{\mathrm{K}, \mathrm{N}, \mathrm{M}\} \text {; }
$$

$$
\mathrm{K}=\left\{\mathrm{k}_{\mathrm{i}}\right\}, \mathrm{i}=1, \cdots, \mathrm{I} ; \mathrm{N}=\left\{\mathrm{n}_{\mathrm{j}}\right\}, \mathrm{j}=1, \cdots, \mathrm{J} ; \mathrm{M}=\left\{\mathrm{m}_{\mathrm{t}}\right\}, \mathrm{t}=1, \cdots, \mathrm{T}
$$

$\mathrm{K}$ is an emotional key dictionary, $\mathrm{N}$ is a negative dictionary, and $\mathrm{M}$ is a modified dictionary. We obtain a large number of 
keywords from the comments, and according to the sentiment lexicon we presented above, we assign each emotional keyword to its specific emotional tendency. Then, we will give a song, collect 500 valid comments below, and set it as a set W:

$$
\mathrm{W}=\left\{\mathrm{w}_{\mathrm{h}}\right\}, \mathrm{h}=1, \cdots, \mathrm{H}
$$

So we convert $\mathrm{W}$ through the emotional key dictionary given above:

$$
\begin{gathered}
\mathrm{U}=\left\{\mathrm{u}_{\mathrm{v}}\right\}=\left\{\mathrm{k}_{\mathrm{i} . \mathrm{v}}, \mathrm{n}_{\mathrm{j} . \mathrm{v}}, \mathrm{m}_{\mathrm{t} . \mathrm{v}}\right\} \\
\mathrm{k}_{\mathrm{i} . \mathrm{v}} \in \mathrm{W} \cap \mathrm{C} ; \mathrm{n}_{\mathrm{j} . \mathrm{v}} \in \mathrm{W} \cap \mathrm{N} ; \mathrm{m}_{\mathrm{t} . \mathrm{v}} \in \mathrm{W} \cap \mathrm{M}
\end{gathered}
$$

Among them, $\mathrm{k}_{\mathrm{i} . \mathrm{v}}, \mathrm{n}_{\mathrm{j} . \mathrm{v}}$, and $\mathrm{m}_{\mathrm{t} . \mathrm{v}}$ appear in each light comment. Based on the above emotional unit, we make the following definition of the emotional vector space model:

$$
\mathrm{V}_{\mathrm{S}}^{\mathrm{i}}=\left(\mathrm{f}_{1}^{\mathrm{i}}(\mathrm{U}), \mathrm{f}_{2}^{\mathrm{i}}(\mathrm{U}), \cdots, \mathrm{f}_{\mathrm{T}}^{\mathrm{i}}(\mathrm{U})\right)
$$

Among them, ViS refers to the emotion vector corresponding to the i-th song, and fij refers to the musical emotion characteristics of the $\mathrm{j}$-th comment. This article summarizes the following six emotional characteristics based on the number of emotional keywords, negative words, and modifiers, as shown in Table 3 below.

TABLE III. MUSICAL EMOTIONAL CHARACTERISTICS TABLE

\begin{tabular}{|c|c|c|}
\hline $\mathbf{f i}$ & \multicolumn{2}{|c|}{ Emotional characteristics } \\
\hline $\mathrm{f} 1$ & positive & $\mathrm{C} 1=\left\{\mathrm{f}_{\mathrm{PSW}}=1, \mathrm{f}_{\mathrm{NSW}}=\mathrm{f}_{\mathrm{NEG}}=0, \mathrm{f}_{\mathrm{MOD}} \geq 0\right\}$ \\
\hline $\mathrm{f} 2$ & negative & $\mathrm{C} 2=\left\{\mathrm{f}_{\mathrm{PSW}}=0, \mathrm{f}_{\mathrm{NSW}}=1, \mathrm{f}_{\mathrm{NEG}}=0, \mathrm{f}_{\mathrm{MOD}} \geq 0\right\}$ \\
\hline $\mathrm{f} 3$ & negative & $\mathrm{C} 3=\left\{\mathrm{f}_{\mathrm{PSW}}=1, \mathrm{f}_{\mathrm{NSW}}=0, \mathrm{f}_{\mathrm{NEG}}=1, \mathrm{f}_{\mathrm{MOD}} \geq 0\right\}$ \\
\hline $\mathrm{f} 4$ & positive & $\mathrm{C} 4=\left\{\mathrm{f}_{\mathrm{PSW}}=0, \mathrm{f}_{\mathrm{NSW}}=1, \mathrm{f}_{\mathrm{NEG}}=1, \mathrm{f}_{\mathrm{MOD}} \geq 0\right\}$ \\
\hline $\mathrm{f} 5$ & positive & $\mathrm{C} 9=\left\{\mathrm{f}_{\mathrm{PSW}}=1, \mathrm{f}_{\mathrm{NSW}}=0, \mathrm{f}_{\mathrm{NEG}}=2, \mathrm{f}_{\mathrm{MOD}} \geq 0\right\}$ \\
\hline $\mathrm{f} 6$ & negative & $\mathrm{C} 10=\left\{\mathrm{f}_{\mathrm{PSW}}=0, \mathrm{f}_{\mathrm{NSW}}=1, \mathrm{f}_{\mathrm{NEG}}=2, \mathrm{f}_{\mathrm{MOD}} \geq 0\right\}$ \\
\hline
\end{tabular}

Among them, $\mathrm{f}_{\mathrm{PSW}}$ represents whether there is a positive emotion keyword in the comment text, $\mathrm{f}_{\mathrm{NSw}}$ represents whether there is a negative emotion keyword in the comment text, $\mathrm{f}_{\mathrm{NEG}}$ represents whether a negative word exists in the comment text, and $\mathrm{f}_{\mathrm{MOD}}$ represents whether there is a modifier word in the comment text.

According to the definition of emotion unit, $\mathrm{f}_{\mathrm{PSW}}, \mathrm{f}_{\mathrm{NSW}}, \mathrm{f}_{\mathrm{NEG}}$, and $\mathrm{f}_{\mathrm{MOD}}$ satisfy the following conditions:

$$
\begin{aligned}
& \mathrm{f}_{\mathrm{PSW}}=\{0,1\}, \mathrm{f}_{\mathrm{NSW}}=\{0,1\}, \\
& \mathrm{f}_{\mathrm{NEG}}=\{0,1,2\}, \mathrm{f}_{\mathrm{MOD}}=\{0,1\} \\
& \mathrm{f}_{\mathrm{PSW}}+\mathrm{f}_{\mathrm{NSW}}=1
\end{aligned}
$$

\section{Experimental verification}

Positioning Figures and Tables: Place figures and tables at the top and bottom of columns. Avoid placing them in the middle of columns. Large figures and tables may span across both columns. Figure captions should be below the figures; table heads should appear above the tables. Insert figures and tables after they are cited in the text. Use the abbreviation "Fig. 1," even at the beginning of a sentence.
1) Manual annotation emotions and modeling calculations

In the experiment, we selected 20 songs of different genre styles, and viewed the 20 songs on the music website that already had emotional tags. We found 11 songs styled as "easy and positive" , and 9 others were marked as

"Repress negative style. First, we invited 20 different respondents to artificially annotate the 20 songs. The main annotations are the two categories of "feeling" and "repression" . In the end, there were 13 songs marked as "easy and positive". The number of correctly labeled songs was 9 and the other 7 were marked as "repressed negative" . Five were correctly labeled. Then, we use the emotional vector space model studied in this paper to extract and analyze the emotional characteristics of the songs. For the above 10 songs, we extracted 200 effective music light comments for each song. Through the emotion vector space method, we obtained that 12 songs were marked as "easy and positive" , in which the number of correctly labeled songs the number is 10 , and the other 8 are marked as "repressed negative," and seven are correctly labeled.

\section{2) Experimental results analysis and evaluation}

We will analyze and measure the accuracy of emotional vector space model and artificial emotion annotation from the three aspects of accuracy rate (p), recall rate (r) and $F$ value (f).Substituting the experimental data, we can draw the following test results:

TABLE IV. MUSICAL EMOTIONAL CHARACTERISTICS TABLE

\begin{tabular}{|c|c|c|}
\hline & Easy songs number & Depressed songs number \\
\hline $\begin{array}{c}\text { Manually labeled } \\
\text { easy songs }\end{array}$ & 9 & 4 \\
\hline $\begin{array}{c}\text { Manually labeled } \\
\text { depressing songs }\end{array}$ & 2 & 5 \\
\hline
\end{tabular}

Recall rate of artificial emotion annotation

$(r)=(9+5) /(9+2+4+5)=0.7$

Manually label positive emotional recall

$(r)=9 /(9+2)=0.82$

Accurate rate of manual annotation of positive emotions

$(p)=9 /(9+4)=0.69$

Manually label positive emotion $\mathrm{F}$

(f) $=0.69 * 0.82 * 2 /(0.69+0.82)=0.75$

Manually label negative emotional recall $(r)=5 /(5+4)=0.56$

Manually label negative emotional correctness

(p) $=5 /(5+2)=0.71$

Manually label positive emotion $\mathrm{F}$

(f) $=0.56 * 0.71 * 2 /(0.56+0.71)=0.63$ 
TABLE V.

EMOTION VeCT OR SPACE MODEL LABELING RESUlt TABLE

\begin{tabular}{|c|c|c|}
\hline & Easy songs number & Depressed songs number \\
\hline $\begin{array}{c}\text { Easy notes for } \\
\text { model annotation }\end{array}$ & 10 & 2 \\
\hline $\begin{array}{c}\text { Depressed songs } \\
\text { marked by } \\
\text { models }\end{array}$ & 1 & 7 \\
\hline
\end{tabular}

Recall rate of model emotional annotation

$(r)=(10+7) /(10+2+1+7)=0.85$

Model annotation positive emotional recall

$(\mathrm{r})=10 /(10+1)=0.91$

Model annotation positive emotion correct rate

$(p)=10 /(10+2)=0.83$

Manually label positive emotion $\mathrm{F}$

$(\mathrm{f})=0.91 * 0.83 * 2 /(0.91+0.83)=0.87$

The model marks negative emotional recall

$(r)=7 /(7+2)=0.78$

Model annotation negative emotion correct rate

$(\mathrm{p})=7 /(7+1)=0.88$

Manually label positive emotion $\mathrm{F}$

(f) $=0.78 * 0.88 * 2 /(0.78+0.88)=0.83$

After comparison, we can find that the data tagged by the emotional vector space model is much larger than the artificial emotion tagging data in terms of accuracy rate, recall rate, and $F$ value. Therefore, we can conclude that using the emotional space model Vectors perform sentiment analysis with high accuracy and productivity. This proves that the emotional space model proposed in this paper is advanced and feasible.

\section{CONCLUSION}

This paper first analyzes the relevant research status and theory in the field of emotional mining. Then it deeply studied the emotions of music and started from the expressions commonly used by Chinese people. Through the emotional analysis of the music light comments, it remodifies and optimizes Hevner's emotional model and the emotional subclasses in it, so as to determine the different adjectives in the music light commentary. The intensity of emotions expressed and the degree of psychological recognition of these adjectives were analyzed, and the emotional polarity and tendency of emotional keywords were analyzed. This paper also proposes an emotional vector space model based on emotion units. Experimental results show that the emotional vector space model has higher accuracy and convenience than artificial emotion recognition.

\section{REFERENCES}

[1] Lee T Y, Bradlow E T. Automated Marketing Research Using Online Customer Reviews[J]. Journal of Marketing Research, 2011, 48(5):881894.

[2] Huang L Q, Tan C H, Ke W L, et al. Comprehension and Assessment of Product Reviews: A Review-Product Congruity Proposition[J]. Journal of Management Information Systems, 2013, 30(3):311-343.

[3] Zhang Yanhui, Li Zongwei, Zhao Yicheng. The Effect of Information Quality Based on Taobao Comment Data on the Usefulness of Online Comments[J]. Chinese Journal of Management, 2017, 14(1):77-85.(In Chinese)

[4] Wang Hongwei,Liu Yi, Yin Wei et al. A Survey of Web Text Sentiment Classification[J]. Journal of the China Society for Scientific andTechnical Information, 2010 (005): 931-938..(In Chinese)

[5] Zhang Ziqiong, Ye Qiang, Li Yijun. A Review of Sentiment Analysis Research on Internet Commodity Reviews[J]. Journal of Management Science, 2010, 13(006): 84-96..(In Chinese)

[6] Abrahams AS, Jiao J, Wang GA, Fan WG. Vehicle defect discovery from social media. Decision Support Systems, 2012,54(1): 87-97. [doi: 10.1016/j.dss.2012.04.005] 